\title{
How to Value GDP-Linked Collar Bonds? An Introductory Perspective
}

\author{
Christophe Schinckus \\ School of Management, University of Leicester, Leicester, UK \\ Email: cs354@le.ac.uk
}

Received March 18, 2013; revised April 23, 2013; accepted May 23, 2013

Copyright (C 2013 Christophe Schinckus. This is an open access article distributed under the Creative Commons Attribution License, which permits unrestricted use, distribution, and reproduction in any medium, provided the original work is properly cited.

\begin{abstract}
This short paper proposed a pricing method for GDP-linked collar bonds based on the classical discounted pricing model and the assumption that the GDP can be described with a geometric Brownian motion. The estimation of parameters was not discussed because it is not central in our numerical exercise.
\end{abstract}

Keywords: GDP-Bonds; Economic Growth

\section{Introduction}

The last financial crisis called the financial sphere into question. In the today's economic environment characterized by weak economic growth, increasing deficits and high risk on financial instrument, recent research in debt literature has focused on mechanisms that could improve the debt instrument for sovereigns in time of macroeconomic climate. Although the existence of economic crises, governments need sometimes to borrow in expectation of better times ahead. However, this kind of sovereign debt can be very costly in an economic climate. In this perspective, academics and specialists tried to develop a more flexible sovereign debt which would be more responding to economic circumstances and would take into account of the evolution of the economic situation of the concerned country: GDP-linked bonds.

For several years, GDP-indexed bonds have generated a lot of research. Schroeder and et al. [1] explained that GDP bonds tend to outperform regular bonds in time of unexpected increase of GPD and under-perform in the presence of unexpected slowdown in the economy while Kamal and Lashgari [2] showed, in a simulation, that GPD bonds would have a superior return than standard government bonds between 1947 and 2010. Some articles also tried to make a theoretical connection between financial mainstream and the pricing of GDP-bonds: Ruben and et al. [3] offered a model founded on an optimizing consumer who evaluates welfare gains from the coupon payments whereas Kruse and et al. [4] applied the Black and Scholes model to value GDP-bonds. An- other perspective is to study the potential link between GDP-bonds and the monetary or fiscal policy. That is the perspective proposed by Miyajima [5] who offered a pricing method based on an incremental tax revenues received by the government to the extra payments on GDP linked bonds.

This paper provides a pricing method for a very specific form of GDP-bonds: the GDP-linked collar bonds. Although this kind of contract is well known in the literature (see Ruben and et al. [3]), few studies often associated them to classical GDP-bonds and did not develop a specific pricing method for these instruments. That is the main objective of this short article.

\section{The Emergence of GDP-Linked Bonds}

The major economic fluctuations cannot be perfectly prevented and a cautious attitude is to try to lessen the impact of those fluctuations on the economic sphere by using appropriate financial instruments. For several years, an increasing number of papers have been dedicated to GDP-linked bonds, emphasizing the stabilizing effect of this kind of new financial vehicle. Indeed, by making the repayment of debts more contingent on economic outcomes, GDP-linked bonds are often presented as automatic stabilizers.

The key feature of a GDP-linked bond refers to the contingency of its cash flows on the evolution of the country's national income (real GDP, nominal GDP or both). In pure financial terms, GDP-indexed bonds can be seen a floating-rate bond with a coupon that would be 
associated with the growth rate of the borrowing country. On a broad level, GDP-linked bonds are desirable instruments for international risk-sharing. Basically, these instruments can benefit not only their holders but also other category of investors because they reduce the likelihood of a default by the borrowing country. More precisely, these bonds "stabilize the government spending and they limit the pro-cyclicality of fiscal pressures by necessitating smaller interest payments at time of slower growth-providing space for higher spending or lower tax" (Griffith-Jones and Sharma [6, p. 2]). Because of the hedging properties (in compensation for inflation, for exnample, see Kamstra and Shiller, [7]) associated with these GDP-bonds the International Monetary Fund and the United Nations have been campaigning for a greater use of these instruments ${ }^{1}$.

The existing examples of debts indexed to GDP are mainly associated with economically stressed countries. In the 1990s, Bulgaria, Bosnian and Herzegovina, Costa Rica and more recently (2005) Argentina issued GDPlinked bonds. However, the potential benefit of these financial vehicles is not only related to emergent countries. Indeed, GDP-linked bonds may also provide benenfits for industrialized countries. In Europe, for example, the hedging properties of these financial instruments could contribute to the Stability and Growth Pact by rendering fiscal policies pro-cyclical. As Shiller [9] explained recently in the The Wall Street Journal, GDP-linked bonds could help government to manage risk by completing (and not replacing) the existing fixed-income securities. Moreover, Shiller [10] did not hesitate to emphasize the political necessity to use these instruments by explaining how they could improve the social security systems: "Social security systems around the world defend the right of the elderly-usually without regard to the situation of the working people who must pay for those entitlements... Government pensions should be indexed to some indicator of taxpayers ability to pay, such as GDP, but it is rarely done” [10, p. 149].

These financial instruments generate a lot of economic and political debates and some organizational problems appeared with the possibility to develop these vehicles. Indeed, the GDP-linked bonds market is not very liquid and this illiquidity makes the pricing of these instruments very complex. Because few countries issued this kind of vehicles, we do not have a critical mass now to maintain liquid market. However, some authors $[2,7,10]$ and financial authorities (IMF, UN) try to favour the emergence of such a market (see Miyajima, [5] for further information on this campaign).

The following section will focus on the presentation a

${ }^{1}$ See $\mathrm{Li}$ [8] for a detailed presentation of potential advantages and disadvantages of GDP-bonds. very specific design of GDP-linked bonds called "GDPlinked collar bonds”. Very few academic researches exist on this particular type of GDP-indexed bonds [3,4]. The next section will provide an introductory perspective on the pricing of these bonds.

\section{GDP-Linked Collar Bonds}

The main advantage of GDP-linked bonds refers to the contingency of debt repayments on the economic outcomes. As mentioned in the previous section, that feature can make the GDP-indexed bonds very interesting especially in a weak economic climate. The question now is what happens in a profitable economic environment? If the growth of GDP increases rapidly, this kind of financial vehicles can be very costly for the country (although this feature would also reduce the temptation for government to spend too much in period of high growth). Basically, the combination of GDP-indexed bonds with a good economic climate could generate economic problems and political protests: while "the need to pay higher interest rates in time of high growth can curb excessively expansionary fiscal policy” (Ruban et al., [3, p. 5]), a significant part of the citizens could argue that the economic growth mainly favour lenders and investors. In other words, a good economic environment could potentially give the bondholder to receive unlimited cashflows. In this perspective, borrowing governments could use more specific bonds avoiding high debt service by fixing a maximum coupon with the following form:

$$
I=\operatorname{Min}\left\{\operatorname{Max}\left[r_{\min }, g_{t}-r_{l e v}\right], r_{\max }\right\}
$$

where $r_{\text {min }}$ is the minimum rate provided by the government, $g_{t}$ refers to the growth rate of GDP, $r_{l e v}$ is the leveraged rate and $r_{\max }$ is the maximum rate the government can offer. In other words, this structure gives the bondholder a minimum coupon of $\left(r_{\min }\right)$ with potential greater cash flow if nominal GDP growth exceeds $r_{\text {lev }}$, but the maximum coupon paid out is capped at $r_{\max }$. Just take the following example. Consider a GPD-linked collar bond with the following indexation:

$$
I=\operatorname{Min}\left\{\operatorname{Max}\left[2 \%, g_{t}-3 \%\right], 13 \%\right\}
$$

That means that the bondholder is sure to have min $2 \%$, he/she will have a variable rate depending on the growth rate of the GDP if this growth is higher than 5\% but the max rate given by the government will be $13 \%$ so that the coupon is capped at $13 \%$. Of course, this kind of indexation raises some questions: how is it possible to value the parameters of this indexation and how to price this kind of bonds? Let's try to give an introductory framework to these questions by continuing with our above example. Given the values provided for each parameter, we can have three potential situations: 


$$
\left\{\begin{array}{l}
g_{t}>13 \% \text { : the coupon with } a \text { maxreturn of } 13 \% \\
5 \%<g_{t}<13 \% \text { : the coupon with an extra-return } \\
g_{t} \leq 5 \% \text { : the coupon with an min return of } 2 \%
\end{array}\right.
$$

where the $g_{t}$ is the current growth rate of $\mathrm{GDP}_{(t)}$. While the two extreme situations provide well known cash flows, the in-between indexation structure must be defined for the pricing of the GDP linked bond. As mentioned above, these extra-returns are due to the evolution of GDP growth rate above a leveraged rate $\left(r_{l}\right)$. Because the long term growth rate can be seen as the most expectable natural level above which governments would have to pay extrainterests, leveraged rate $\left(r_{t}\right)$ can be associated with the average long-term growth rate observed for the GDP. In statistical terms, the real output (real GDP trend) can be expressed as a geometric Brownian motion,

$$
\text { Real GDP Trend }=\mathrm{d} \bar{Y}_{t}=g \bar{Y}_{t} \mathrm{~d} t+\sigma \bar{Y}_{t} \mathrm{~d} Z
$$

where $g$ determines the expected long run sustainable growth rate and $\sigma$ represents the amount of fluctuations (volatility) in the GDP.

$$
\mathrm{d} y_{t}=y_{t}\left(g+\sigma \varepsilon_{t}\right)
$$

where $\varepsilon_{t}(i=1, \cdots, N)$ are random draws from $\varnothing(0,1)$. Hence,

$$
y_{t}=y_{0} \prod\left(1+g+\sigma \varepsilon_{t-N}\right)
$$

By taking into account of the inflation $\delta$, we can write,

$$
y_{t}=y_{0} \prod\left(1+g+\sigma \varepsilon_{t-N}\right)\left(1+\delta_{t-N}\right)
$$

Actual growth rate which could influence the coupon is given by

$$
g_{t}=\frac{\mathrm{d} y_{t}}{y_{t}}
$$

If the observed growth rate of the GDP exceeds the statistical observed long term growth rate (associated here with the leveraged rate, $r_{l e v}$ ), the government will have to pay extra cash flow ${ }^{2}$. In this perspective then, the extra cash flows given by the government can be written,

$$
\text { Extra } C F=\left(g_{t}-g\right) y_{t}
$$

By knowing (6) and (7), extra cash flows can be rewritten as follows,

$$
\begin{aligned}
\operatorname{Extra} C F= & \left(\left(\frac{y_{t}\left(g+\sigma \varepsilon_{t}\right)}{y_{0} \prod\left(1+g+\sigma \varepsilon_{t-N}\right)\left(1+\delta_{t-N}\right)}\right)-g\right) \\
& \times\left[y_{t} \prod_{N=0}^{t-1}\left(1+g+\sigma \varepsilon_{t-N}\right)\left(1+\delta_{t-N}\right)\right]
\end{aligned}
$$

\footnotetext{
${ }^{2}$ This is a deduction from a classical assumption in macroeconomics. However, the estimation of this leveraged rate needs further discussions. Because this paper focuses on the pricing method, I do not discuss the estimation of parameters but I plan to do it in further research.
}

$$
\text { Extra } C F=\sigma \varepsilon_{t} y_{0} \prod_{N=0}^{t-1}\left(1+g+\sigma \varepsilon_{t-N}\right)\left(1+\delta_{t-N}\right)
$$

That means that the bondholder could apply this indexation structure to his/her coupon:

$$
I=\operatorname{Min}\left\{\operatorname{Max}\left[r_{\min } \text {, Extra Cash Flow }\right], r_{\max }\right\}
$$

In this perspective, each coupon payment in nominal terms would then be discounted by the domestic real interest rate $i$ and is deflated by the cumulative inflation rates,

$$
C(I)=\frac{\operatorname{Min}\left\{\operatorname{Max}\left[r_{\min }, \text { Extra Cash Flow }\right], r_{\max }\right\}}{\prod_{N=0}^{t-1}\left(1+i_{t-N}\right)\left(1+\delta_{t-N}\right)}
$$

The pricing of the bond would then be given by the expected

$$
P=\sum_{t} E[C(I)]
$$

This section shows that GDP-linked collar bonds can be valued with few economic parameters (interest rate, inflation rate and GDP growth rate). This valuation in line with the classical economic mainstream could pave the way to a more generalized use (and research) of this GDP-linked collar bonds.

\section{Conclusion}

This paper proposed a pricing method for GDP-linked collar bonds. The estimation of every parameter was not discussed because it was not central in the numerical exercise. This introductory method will be tested through empirical studies that I plan to do in different economic contexts whose conditions will be modelled by using Monte Carlo methods. In this perspective, the economic justification for the choice of every parameters $\left(r_{\min }, r_{l e v}\right.$, $r_{\max }$ ) will be discussed in more details.

\section{REFERENCES}

[1] M. Schröder, F. Heinemann, S. Kruse and M. Meitner, "GDP-Linked Bonds as a Financing Tool for Developing Countries and Emerging Markets,” ZEW Discussion Paper 04-64, Centre for European Economic Research, Mannheim, 2004.

[2] L. Kamal and M. Lashgari, "Comparing GDP Indexed Bonds to Standard Government Bonds," Journal of Applied Business and Economics, Vol. 13, No. 2, 2012, pp. 116-128.

[3] O. Ruban, Sh. Poon and K. Vonatsos, "GDP Linked Bonds: Contract Design and Pricing,” Working Paper, Manchester Business School, 2008.

[4] S. Kruse, M. Meitner and M. Schröder, "On the Pricing of GDP Linked, Financial Products,” Applied Financial Eco- 
nomics, Vol. 15, No. 16, 2005, pp. 1125-1133. doi:10.1080/09603100500359260

[5] K. Miyajima, "How to Evaluate GDP-Linked Warrants: Price and Repayment Capacity,” IMF Working Paper, WP06/85, 2006.

[6] S. Griffith-Jones and K. Sharma, "GDP-Indexed Bonds: Making It Happen,” UN/DESA Working Paper, No. 21, 2006.

[7] M. Kamstra and R. Shiller, "The Case of Trills: Giving the People and Their Pension Funds a Stake in the Wealth of the Nation," Cowles Foundations Discussion Paper Series, 2009.

[8] L. Li, "Macroeconomic Factors and the Correlation of Stock and Bond Returns," Working Paper, Yale University, Vol. 118, 2002, pp. 1-39.

[9] R. Shiller, "Worried about US debt? Shiller Pushes GDPLinked Bonds,” The Wall Street Journal, 17 February 2011.

[10] R. Shiller, "Finance and Society," Princeton University Press, Princeton, 2012. 